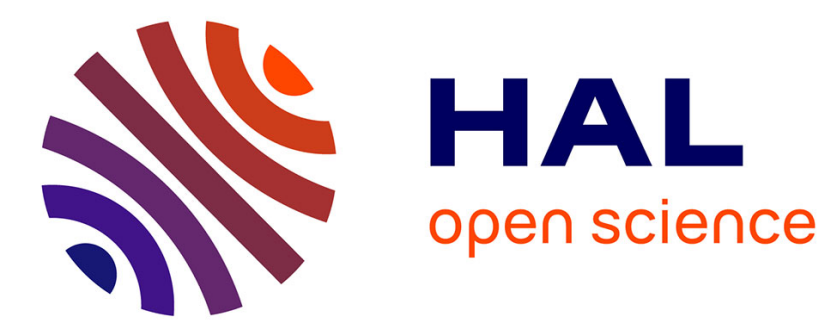

\title{
Passage of a bubble through a liquid-liquid interface
}

\author{
N. Dietrich, S. Poncin, S. Pheulpin, H.-Z. Li
}

\section{To cite this version:}

N. Dietrich, S. Poncin, S. Pheulpin, H.-Z. Li. Passage of a bubble through a liquid-liquid interface. AIChE Journal, 2008, 54 (Issue 3), pp.594-600. 10.1002/aic.11399 . hal-00344990

\section{HAL Id: hal-00344990 https://hal.science/hal-00344990}

Submitted on 23 Jul 2021

HAL is a multi-disciplinary open access archive for the deposit and dissemination of scientific research documents, whether they are published or not. The documents may come from teaching and research institutions in France or abroad, or from public or private research centers.
L'archive ouverte pluridisciplinaire HAL, est destinée au dépôt et à la diffusion de documents scientifiques de niveau recherche, publiés ou non, émanant des établissements d'enseignement et de recherche français ou étrangers, des laboratoires publics ou privés. 


\title{
Passage of a bubble through a liquid-liquid interface
}

\author{
N. DIETRICH, S. PONCIN, S. PHEULPIN and Huai Z. LI
}

Laboratoire des Sciences du Génie Chimique, CNRS-ENSIC-INPL, 1 rue Grandville, BP 20451, 54000 Nancy Cedex, France

Keywords: Liquid-liquid interface, Deformation, Bubble, PIV

\begin{abstract}
The aim of this study is to investigate the bubble passage at a liquid-liquid interface using a high-speed video camera (950 images per second) and a Particle Image Velocimetry system (PIV). Experiments were conducted in a square Plexiglas column of $0.1 \mathrm{~m}$. Bubbles were generated through a submerged orifice $\left(\mathrm{D}=1 \times 10^{-3} \mathrm{~m}\right)$. The Newtonian Emkarox (HV45) solution was employed for the heavy phase while two different organic liquids of different viscosity (Silicone oil $10 \mathrm{mPa} . \mathrm{s}$ and $100 \mathrm{mPa} . \mathrm{s}$ ) were used as light phase. Experimental results show the effect of the bubble size and the viscosity of the light phase on the retention time, the length of the column of fluid entrained behind the bubble, the bubble velocity as well as the velocity fields at the liquid-liquid interface.
\end{abstract}

\section{Introduction}

Interfacial phenomena are widely involved in liquid-liquid or liquid-gas multiphase systems. Drop or bubble sizes, fluid's rheology, hydrodynamics and mass transfer depend not only on the properties of the bulk phase but also on the composition, the 
structure and the physical characteristics of the interface like interfacial tension and contact angle. Liquid-liquid interfaces play an important role in emulsification processes, mass transfer such as liquid-liquid extraction and numerous chemical reactions. The understanding of a liquid-liquid interface at meso- and microscale and in particular the knowledge of its deformation and forces stemming from the passage of a bubble are of key importance for developing and optimizing liquid-liquid interface technologies. In order to gain insight into the fundamental mechanisms governing the emulsification, mass transfer or chemical reactions between two immiscible liquid phases, the present work aims at studying the dynamical behavior of liquid-liquid interfaces under a controlled solicitation through the passage of a rising bubble of desired size. Besides the potential industrial applications (many industrial contacting devices for separation and mixing involve interfacial phenomenon where interface crossing can occur), our results can also provide the numerical modeling and simulation with adequate experimental validation for the boundary conditions at an interface.

Rankine $^{1}$, Maxwell ${ }^{2}$ and Havelock ${ }^{3}$ studied the trajectories of fluid particles disturbed by the passage of a rigid cylinder in a perfect fluid. In the frame moving with the cylinder, the fluid particles trace out streamlines, but, in the fluid frame of reference, these trajectories are extremely complex, consisting of a large-scale looping motion and a permanent displacement forward where the cylinder passes. In order to quantify the interface behavior and the ability of bodies to transport fluid from one place to another, Darwin $^{4}$ developed, for potential flows, the concept of the drift volume. Darwin considered how a body moving in a straight line in an unbounded flow permanently deforms a material surface, which is initially far in front of the body. Darwin defined the drift volume as the volume formed between the initial and the final position of the material surface and was able to calculate it. Based on a result of Darwin concerning 
hydrodynamic mass, Lighthill ${ }^{5}$ computed the drift, tabulated the secondary vorticity field in shear flow past a sphere and also studied the asymptotic form of the secondary velocity field in flow past any body.

An important number of studies and reviews in the literature focus on the penetration of particles through liquid-liquid interfaces between two immiscible liquids. These studies reported plausible scenarios associated with such breaks through, when the migrating particles are in a different phase than the liquids or when the particles coalesce with the second liquid after their passage through the first one. A number of experiments and theoretical analysis have been reported on the film drainage. These experiments show that in the case of solid particle sedimentation ${ }^{6}$, the film breakthroughs in many points favors drop formation in the heavy phase, whereas for drop sedimentation, the film breaks in a single point.

The study of a rising bubble through a liquid-liquid interface concerns generally the evolution of the velocity and the shape of the bubble in each phase and also the behavior of the interface before and after the passage of the bubble. Lin and Slattery ${ }^{7}$ studied the interface deformation during the passage of a bubble or a drop and also the film drained behind the bubble or the drop. They developed a simple hydrodynamic model for the drainage of a liquid film as a small drop or bubble approaches a fluid-fluid interface. However, they supposed the effects of London-van der Waals forces and electrostatic forces to be negligible. Chen et al. ${ }^{8}$ extended this model including the effects of these forces. Bhaga and Weber ${ }^{9}$ considered the fluid displacement associated with bubbles rising along the axis of a cylindrical tube. As reported by Bush and Eames ${ }^{10}$, Bataille et $a l{ }^{11}$ examined air bubbles rising through an interface between two aqueous solutions at Reynolds numbers ranging from 500 to 1300, but did not provide any description of the shape, the wake and the motion of the bubble. Manga and Stone ${ }^{12}$ studied the passage of 
a particle thought a liquid-liquid interface at low Reynolds numbers. From experimental measurements, they noted that the film behind the bubble breaks into small droplets which settle to the interface and coalesce due to surface instabilities. These authors underline the role of surface instabilities for this phenomenon. Bush and Eames ${ }^{10}$ who investigated experimentally the motion of bubbles at high Reynolds numbers, noted the deformation of the interface and estimated the drift volume. They underlined the rapid coalescence of droplets caused by the high pressure inside the droplets due to gravity and tension forces. Mohamed-Kassim and Longmir ${ }^{13}$ examined the coalescence of drops through liquid/liquid interfaces using Particle Image Velocimetry (PIV). They studied the effect of liquid viscosity at similar liquid density and for different Reynolds numbers. These authors show that the film drainage which occurs before the rupture is due to interfacial forces and is dissymmetric most of the time. After the interface's break, coalescence happened very quickly. Following the rupture of film, the coalescence between the resulting droplets happens very quickly due to the internal pressure.

On the numerical and theoretical side, several works were carried out concerning the deformation of the interface (Lee and Leal ${ }^{14}$, Manga and Stone ${ }^{12}$, and Eames and Duursma $^{15}$ ). Shopov and Minev ${ }^{16}$ studied numerically and experimentally the passage of a particle (drop or bubble) through a liquid-liquid interface under different Reynolds numbers in Newtonian media. They considered mainly the effect of the initial shape of bubble on the evolution of the deformation of the interface before its crossing by the bubble. Based on the balance between inertial, gravitational, viscous and interfacial forces, they concluded that the initial shape of the bubble does not have a noticeable influence on the deformation of the interface. While a great deal of research has been focused on the understanding of the bubble behavior and characteristics in Newtonian 
fluids and non-Newtonian fluids (Funfschilling and $\mathrm{Li}^{17,18}$ ), only few experimental studies concern the bubble crossing interface obtained between a heavy and a light immiscible fluids. The aim of this work is to investigate, using a high speed camera as well as a PIV system, the bubble passage at a liquid-liquid interface using Newtonian liquids.

\section{Experimental setup}

The experiments were conducted in a square Plexiglas column (inner dimensions: $0.1 \mathrm{~m}$ width, $0.5 \mathrm{~cm}$ high) filled with different oil and aqueous phases. The gas bubbles were generated through a submerged orifice of $1 \times 10^{-3} \mathrm{~m}$ diameter located at the centre of the bottom section of the column. An electronic valve of rapid response controlled by a personal computer permitted the injection of bubbles of determined volume at desired injection interval. In these experiments, air bubbles were always generated individually. All experiments were carried out at constant temperature of $293 \mathrm{~K}$. The visualization of the phenomenon was realized by a high-speed digital video camera (VNR 950, SYSMA INDUSTRIE) at a rate of 950 images per second, for record grey valued images with a size of $256 \times 256$ pixels. The light was provided by an indirect $800 \mathrm{~W}$ halogen which enlightens the column via indirect lighting on a white screen placed behind the bubble column. The image sequences obtained were then analyzed in order to calculate the position, the velocity and the bubble drain.

In this work, three different liquids were considered as light phase: Silicone oil 47V10, 47V50 and 47V100. The heavy liquid were viscous Newtonian Emkarox 50\% and 65\% (wt) (HV45) dilute solution in demineralized water. A Rheometric Fluid Spectrometer RFS II (Rheometric Scientific) was employed to measure the rheological properties. Table 1 lists properties of the various liquids used. The surface and interfacial tensions 
of the solutions were measured using a Tracker tensiometer (I.T. Concept, France) and are reported in table 2.

Instantaneous velocity fields around a rising bubble were measured (Fig. 1) using a Particle Image Velocimetry (PIV) device (Dantec Dynamics, Denmark). Illumination sheets were generated by two pulsed Nd-YAG LASERS (SOLO-I-15 PIV New Wave Research, USA) arranged side-by-side and crossed the vertical symmetry axis of the bubble. The energy produced by this source was $2 \times 15 \mathrm{~mJ}$. These green lasers with a wavelength of $532 \mathrm{~nm}$ had an emission duration of 8 to $10 \mathrm{~ns}$. The time interval between two consecutive illuminations ranged from less than one microsecond to a few milliseconds. The Nd-Yag lasers were also designed to ensure a sequence of illumination at a frequency of $15 \mathrm{~Hz}$. The laser beams crossed first a cylindrical lens and obtained laser sheets of strong light intensity and low thickness $\left(2.5 \times 10^{-3} \mathrm{~m}\right.$ maximum $)$. They were focused and superposed on one zone of measurement.

The size of the seeding particle has to be chosen so that the particles follow correctly the flow and produce a sufficient light to make the recording possible and minimize the errors of measurements. Generally, diameters of particles going from 10 to 50 micrometers were used for liquids. Seeding particles used in this study were composed of silvered glass microspheres of size going from 10 to 30 micrometers (average diameter of 15 microns) and of a density of $1400 \mathrm{~kg} \cdot \mathrm{m}^{-3}$. The camera, placed perpendicular to the laser sheets, took two successive images at the maximum intensity of the laser impulse. These images were divided into a few thousands of small interrogation areas of $16 \times 16$ pixels. A cross-correlation was then performed between the corresponding interrogation areas. The liquid flow field as well as the bubble rise velocity were thus obtained. When the flow was correctly inseminated, the measurement errors of the measured velocities were less than $5 \%$. 
From these experiments, one can determine the instantaneous bubble rise velocity at different positions in the column as well as its terminal rise velocity $U$. Due to the relatively high value of the viscosity of both fluids, it was observed that the acceleration of a bubble after detachment was quickly absorbed by the liquid and the terminal rise regime was then reached at about $0.1 \mathrm{~m}$ above the orifice whatever the bubble volume used in this study.

\section{Experimental results}

When a bubble rises in a liquid and through a liquid-liquid interface, the resulting behavior can be quite different. The reduced density difference and the enhanced viscous shearing between both liquids tend to limit the bubble impact velocity in gravity-driven flow. Furthermore, as the interfacial force is additional to the elastic and viscous forces, then, the bubble and the interface deform both significantly. The layer of the dense surrounding liquid between the bubble and the liquid-liquid interface, termed a 'thin film', prevents the bubble from reaching the light phase instantaneously. The pressure gradient causing film drainage is opposed by viscous effects in the film.

When the film becomes sufficiently thin, intermolecular forces begin to play a significant role before its rupture. During the approach towards the interface, the bubble entrains a column of the heavy liquid which follows it through the interface. The rupture between this column of the heavy liquid and the bubble occurs in the light phase later than the first rupture of the thin film (between the bubble front and the interface). Finally, the bubble continues its rise in the light phase, to reach its terminal rise velocity. 
The experimental results will first be presented for the HV45 50\%/Silicone oil 10 system. Figure 2 shows the different steps during the passage of a bubble of $200 \times 10^{-9}$ $\mathrm{m}^{3}$ volume (diameter of $7.1 \times 10^{-3} \mathrm{~m}$ ) through the liquid-liquid interface. The first set of frames shows the bubble in the heavy fluid, where it is cup-shaped and rises slowly with a terminal velocity of about $0.11 \mathrm{~m} \mathrm{~s}^{-1}$. The subsequent frames illustrate successively the arrival of the bubble at the liquid-liquid interface, the deformation and the stretching of the interface during the crossing of the bubble and finally the rupture of the film as the bubble rises in the light phase. As it crosses the liquid-liquid interface, the bubble slows down and assumes an elliptical shape which finally becomes oblate in the less viscous light phase with a higher terminal rise velocity of about $0.18 \mathrm{~m} \cdot \mathrm{s}^{-1}$. The rise of the bubble in the upper fluid layer is accompanied by the stretching and the drainage of the heavy liquid film.

The position of the bubble is shown in Figure 3 as a function of time for two different liquid-liquid systems using the same heavy phase (HV $4550 \% \mathrm{wt}$ ) and two different light liquid phases (Silicone 10 and Silicone 100) for a given bubble volume of $200 \times 10^{-}$ ${ }^{9} \mathrm{~m}^{3}$. One can observe that the viscosity of the upper phase has a significant influence on the time spent by the bubble at the interface.

For systems involving the same dense phase, the time spent by the bubble at the interface is bigger in the case of the more viscous silicone oil 100 than for the less viscous silicone oil 10 in the upper layer. This tendency may be influenced by the slightly lower value of the interfacial tension of HV45 50\%-Silicone 10 system and the viscosity difference between the two phases. Furthermore, the terminal bubble rise velocity in the heavy phase (velocity of $0.11 \mathrm{~m} \cdot \mathrm{s}^{-1}$ ) is close to that in the light silicone 100 oil phase (velocity of $0.12 \mathrm{~m} . \mathrm{s}^{-1}$ ) as compared to that obtained in the silicone 10 oil (velocity $0.18 \mathrm{~m} \cdot \mathrm{s}^{-1}$ ). The evolution of the length of the column of liquid entrained by 
the bubble with the bubble volume is reported in Figure 4 for both light phases used in this study. Once again, one can observe the significant effect of the light phase viscosity on the height of this column before its rupture. The length of the column is more important with of silicone 10 than for silicone 100 for a given bubble size. The distance travelled before the rupture, increases with bubble size for a given liquid-liquid system. In general, the larger the bubble, the greater will be the entrainment of liquid behind it and the larger the diameter of the entrained column. With the same size of bubble, the lengths of film are greater in the case of the interface HV50\%/silicone oil 10 than in case of HV50\%/ Silicone oil 100, certainly due to the difference in interfacial tension and viscosity which may dampen the coalescence process. The comparison of the stretching film length of the interface shows that this length decreases with the increase of the viscosity of the oil phase. In addition, it increases with the viscosity of the aqueous phase for the systems having the same oil phase.

The physical properties of each system play a main role both in the time spent by the bubble at the interface and in the stretch length of liquid. To highlight this effect, Table 2 represents the characteristic parameters obtained for various interfaces and bubble sizes. Table 2 shows that the time of the bubble passage is significantly affected by the bubble size and the viscosity of both dense and light phases. This parameter normally decrease with the increase of the bubble size, for a given liquid-liquid system, and increase with the viscosity of the dense or the light phase for a fixed bubble diameter. The variation of the time spent by the bubble at the interface (cf. Fig. 3) and the stretch length of the interface (corresponding to the column of dense liquid entrained in the light phase) obtained for the various systems in this work are represented by dimensionless numbers that could describe this phenomenon. The principal forces 
controlling the phenomenon are viscosity force, inertia and surface tension (surface and interfacial) so Reynolds and Weber numbers were chosen.

The Reynolds numbers, $\mathrm{Re}_{1}$ and $\mathrm{Re}_{2}$, are based on the terminal bubble rise velocities obtained in the dense and light phase respectively. Table 2 underlines also the dimensionless Weber number of both phases, the diameter equivalent of the bubble, the time of passage of bubble (i.e. time that the bubble needs to cross the interface) and also the maximum length of the column of liquid entrained by the bubble. Table 2 shows that the bubble passage time depends significantly on the bubble diameter. This can be explained by the increase of inertial forces and buoyancy, principal driving forces acting on the bubble. In contrary, the influence of the bubble size on the stretch length of the interface $\left(\mathrm{h}_{\max }\right)$ seems to play a moderate role.

A dimensionless number based on the passage time (Eq. 1) was chosen to correlate the experimental results. This number defined by the ratio between the passage time $t_{p}$ and the characteristic time of the bubble in the aqueous phase $t_{c}$ (i.e. the time necessary that the bubble crosses a distance equal to its equivalent diameter) is defined as follows.

$$
\mathrm{t}_{\mathrm{c}}=\frac{\mathrm{d}_{\text {equivalent }}}{\mathrm{U}_{\text {terminal }}}
$$

where $U_{\text {terminal }}$ is the terminal rise velocity of the bubble.

Fig. 5 shows that the passage time increases with $\mathrm{Re}_{1} / \mathrm{Re}_{2}$ ratio following a power law:

$$
\frac{t_{p}}{t_{c}}=2.72\left(\frac{\mathrm{Re}_{1}}{\mathrm{Re}_{2}}\right)^{0.34}
$$

Furthermore, this time increases with the viscosity of the aqueous phase due to the inertial force.

The measurements of flow fields could give further information about the breakthrough mechanism and the length of the column entrained behind the bubble. The major 
difficulty in applying the PIV technique to measure free surface flows in the vicinity of the interface arises from the light reflection from the liquid-liquid and gas-liquid interfaces. The light reflected at theses interfaces is normally much more intense than the light scattered by the tracer particles, thus preventing the registration of their images on the recording media. The tracer particles chosen were glass microspheres with a mean diameter of $15 \mu \mathrm{m}$ and are used in both phases. Figure 6 shows the problems of light reflection and of obscurity obtained near the bubble due to its shadow. These problems led to a lack of information on the right side of the flow field, especially for small bubbles. So we decided to work with bubble volumes larger than $50 \times 10^{-9} \mathrm{~m}^{3}$ (average velocity around $0.05 \mathrm{~m} \cdot \mathrm{s}^{-1}$ ).

The experimental flow fields obtained during the transit of a bubble of $200 \times 10^{-9} \mathrm{~m}^{3}$ $\left(7.1 \times 10^{-3} \mathrm{~m}\right.$ equivalent diameter) through the HV45 50\%/Silicone oil 10 interface are shown in Figures 7 and 8 . The time between successive frames is $5 \mathrm{~ms}$. The choice of this time is very important on view of the rapidity of the physical phenomena.

For visualization, the interface and the bubble shape are superposed on the flow field. Before the arrival of the bubble, no change is of course observed in the successive flow fields. During the rise of the bubble in the heavy phase far from the interface, no change is observed in the light phase. However, an evolution of the flow field similar to that obtained for ascension in an infinite fluid is obtained around the bubble in the heavy phase with an upward flow at the front and in the wake of the bubble, and recirculation loops on lateral sides of the bubble.

When the bubble approaches the interface, the liquid-liquid interface is deformed due to the upward flow at the front of the bubble (Fig 2). When the bubble crosses the liquidliquid interface, it entrains a column of the heavy liquid. An ascension of the fluid of the 
lower phase is observed behind the bubble when it rises through the interface and recirculation loops appear at both lateral sides of the bubble.

As the bubble crosses the interface, which is illustrated in Figure $7 \mathrm{a}$, one observes an upward flow of the entrained column of the heavy liquid phase behind the bubble and a circulation loop adjacent to the bubble in the light phase. Figures $7 \mathrm{~b}, 8 \mathrm{a}$ and $8 \mathrm{~b}$, show the progressive stretching and thinning of the column of the liquid behind the bubble. In these figures, one can also observe, at a certain height within the column, above the initial position of the interface, a downward flow exists inside the column below this position whereas an upward flow still exists in the wake of the bubble.

Circulation loops appear in the light phase external to the bottom of the column in the opposite direction to those observed adjacent to the bubble. This behavior contributes to the progressive thinning of the column of the liquid, leading to rupture. This movement appears to be symmetric, within the constraints imposed by the visualization method due to internal reflection. After rupture, the bubble rises in the light phase with a more elongated shape due to the light phase properties. The column of heavy liquid falls down to its own phase, together with droplets that form due to the breakup of the thin film. In order to understand and visualize the importance of viscosity, the difference on the velocity fields was studied for two different interfaces. Figures $9 \mathrm{a}$ and $9 \mathrm{~b}$ show the difference between velocity fields obtained using two different viscosities of light phase. The recirculation region expands in space with a decrease of the lightest phase viscosity, resulting from a bigger bubble velocity in this phase.

\section{Conclusion}

This present work allows the visualization and validation of the mechanism of liquidliquid interface breakthrough by the passage of a bubble. Flow field measurements obtained by the PIV device contribute to the understanding of the different steps 
encountered during the film thinning and rupture. The mechanism and the visualization of the bubble passage through an interface can give a lot of useful information for the numerical analysis of the film rupture which can take place in many industrial process like emulsification.

\section{Acknowledgements}

The financial assistance provided by the French Ministère de l'Education Nationale, de la Recherche et de la Technologie is gratefully acknowledged.

\section{Literature Cited}

1. Rankine WJM. On plane water lines in two dimensions. Phil. Trans. R. Soc. Lond. 1864;154:369-391.

2. Maxwell JC. Scientific papers. New York: Dover, 1870:210-212.

3. Havelock, TH. The displacement of particles in a case of fluid motion. Proc. Univ. Durham Phil. Soc. 1910;3:62-79.

4. Darwin C. A note on hydrodynamics. Proceedings of the Cambridge Philosophical Society. 1953;49:342-354.

5. Lighthill MJ. Drift. Journal of Fluid Mechanics, 1956;1:31-53

6. Maru HC, Wasan DT, Kintner RC. Behavior of a Rigid Sphere at a LiquidLiquid Interface. Chemical. Engineering Science. 1971;26:1615-28.

7. Lin CY, Slattery JC. Thinning of a liquid film as a small drop or bubble approaches a solid plane. AIChE Journal. 1982;28:147-156.

8. Chen JD, Hahn PS, Slattery JC. Coalescence time for a small drop or bubble at a fluid-fluid interface. AIChE Journal. 1984;30:622-630.

9. Bhaga D, Weber ME. Bubbles in viscous liquids: Shapes, wakes and velocities. Journal of Fluid Mechanics. 1981;105:61-85. 
10. Bush JWM, Eames I. Fluid displacement by high Reynolds number bubble motion in a thin gap. International Journal of Multiphase Flow. 1997;24:411430.

11. Bataille J, Lance M, Marie JL. Some aspects of the modelling of bubbly flows. In "Phase-Interface Phenomena in Multiphase Flows". 1991;179-193.

12. Manga M, Stone HA. Interactions between bubbles in magmas and lavas: effects of bubble deformation. Journal of Volcanology and Geothermal Research. $1994 ; 63: 267-279$.

13. Mohamed-Kassim Z, Longmir EK. Drop coalescence through a liquid/liquid interface. Physics of Fluids. 2004;16:2170-2181.

14. Leal LG, Lee SH. Particle motion near a deformable fluid interface. Advances in Colloid and Interface Science. 1982;17:61-81.

15. Eames I, Duursma G. Displacement of horizontal layers by bubbles injected into fluidised beds. Chemical Engineering Science, 1997;269-2705

16. Shopov PJ, Minev PD. Unsteady interaction of two deformable drops. Mechanics Research Communications. 1991;18:311-317.

17. Frank X, Li HZ, Funfschilling D, Burdin F, Ma Y. Bubble motion in nonNewtonian fluids and suspensions. Canadian Journal of Chemical Engineering. 2003;81: 483-490.

18. Funfschilling D, Li HZ. Flow of non-Newtonian fluids around bubbles: PIV measurements and birefringence visualisation. Chemical Engineering Science. $2003 ; 56: 1137-1141$ 


\section{Caption of figures}

Figure 1. PIV system set up.

Figure 2. Passage of a $200 \times 10^{-9} \mathrm{~m}^{3}$ bubble through the interface HV45 50\% / Silicone oil 10 .

Figure 3. Evolution of the bubble's retention time for two different light phases.

Figure 4. Evolution of the film's maximum length before rupture.

Figure 5. Variation of the ratio between the time of passage of the bubbles over the characteristic time in the various systems studied according to the Reynolds numbers $\operatorname{ratios}\left(\operatorname{Re}_{1} / \operatorname{Re}_{2}\right)$.

Figure 6. Example of images obtained at the interface with tracer particles (reflection comes from the interface).

Figure 7. Flow fields around a $200 \times 10^{-9} \mathrm{~m}^{3}$ bubble crossing the interface obtained by PIV measurements (a) $\mathrm{t}=0.2 \mathrm{sec}$ after the interface contact (b) $\mathrm{t}=0.3 \mathrm{sec}$ after the interface contact.

Figure 8. Flow fields around a of $200 \times 10^{-9} \mathrm{~m}^{3}$ bubble trough an interface by PIV measurements (a) $\mathrm{t}=0.4 \mathrm{sec}$ after the interface contact (b) $\mathrm{t}=0.6 \mathrm{sec}$ after the interface contact and just before the rupture.

Figure 9. Comparison of velocity fields for two different interfaces for a $200 \times 10^{-9} \mathrm{~m}^{3}$ bubble (a) HV45 50\% / Silicone oil 100. (b) HV45 50\% / Silicone oil 10.

Table 1. Properties of the different liquids used in this study

Table 2. Parameters of the phases for different systems 


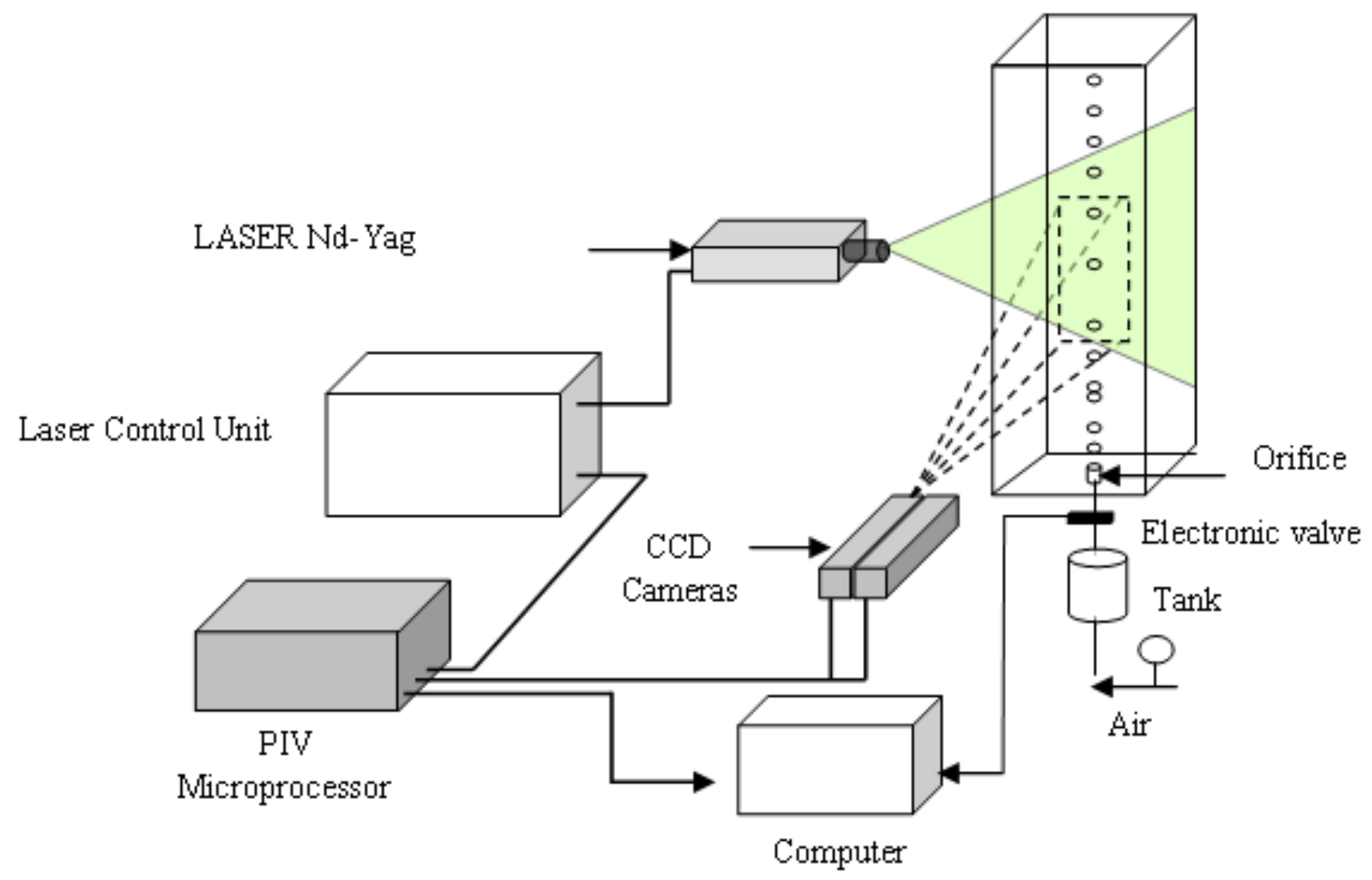




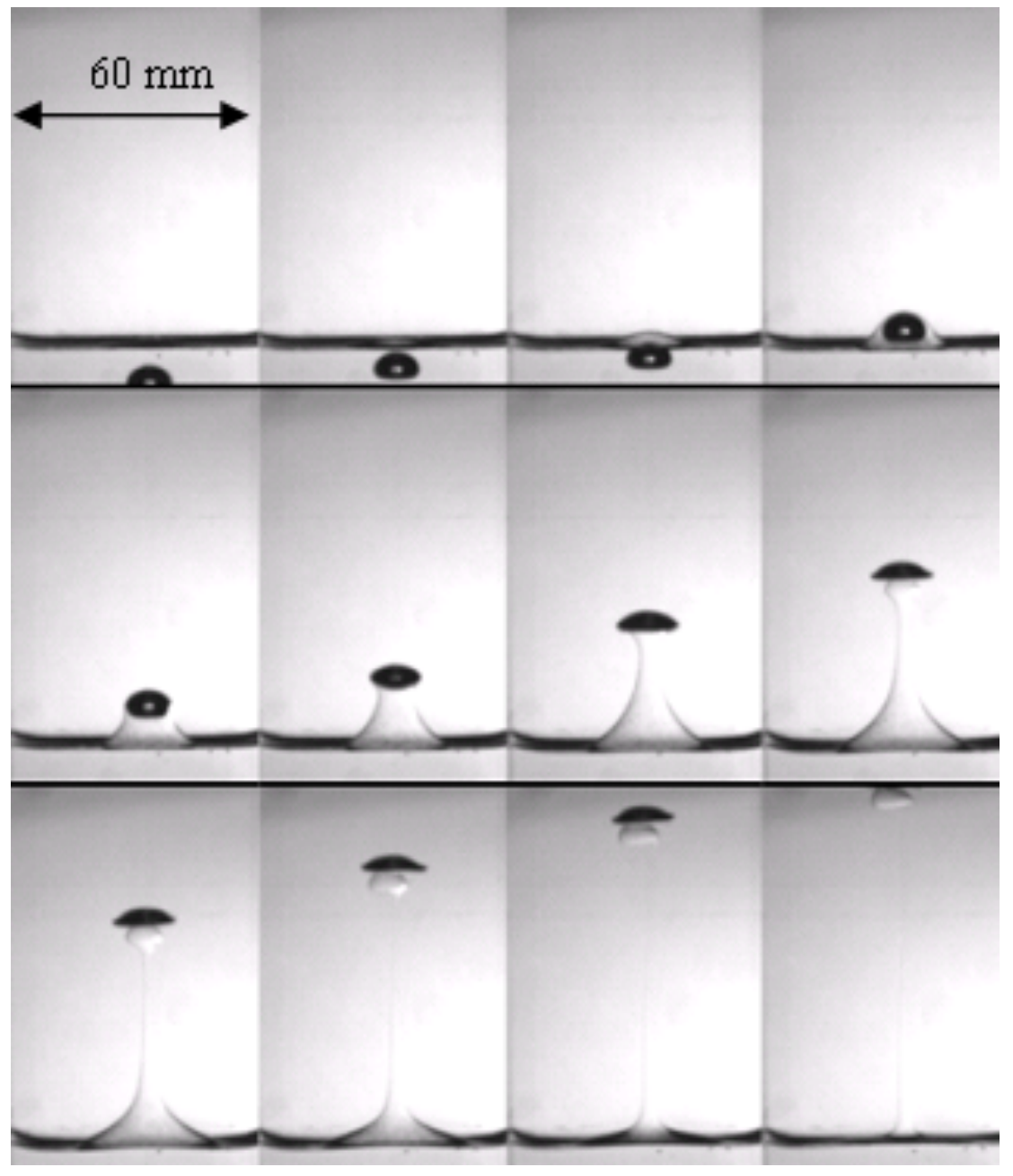




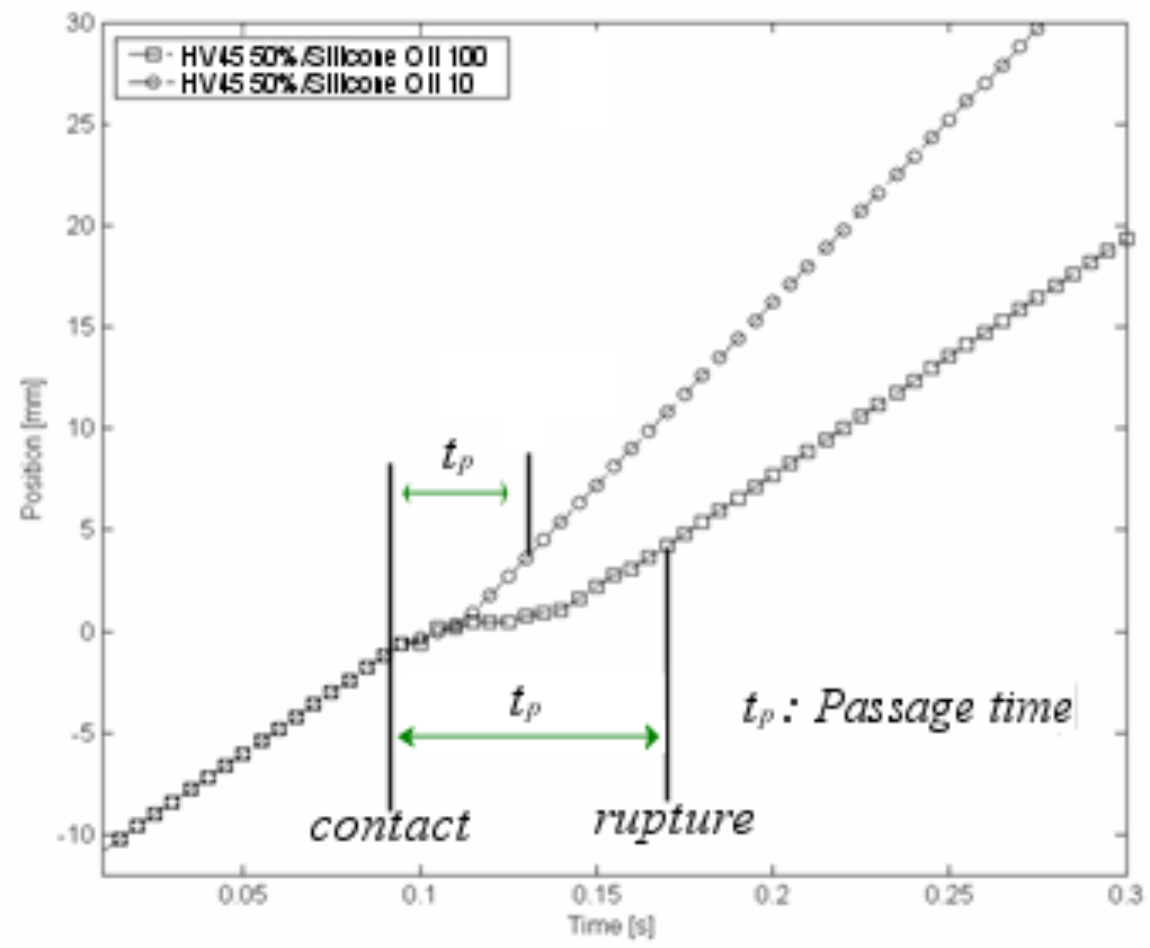




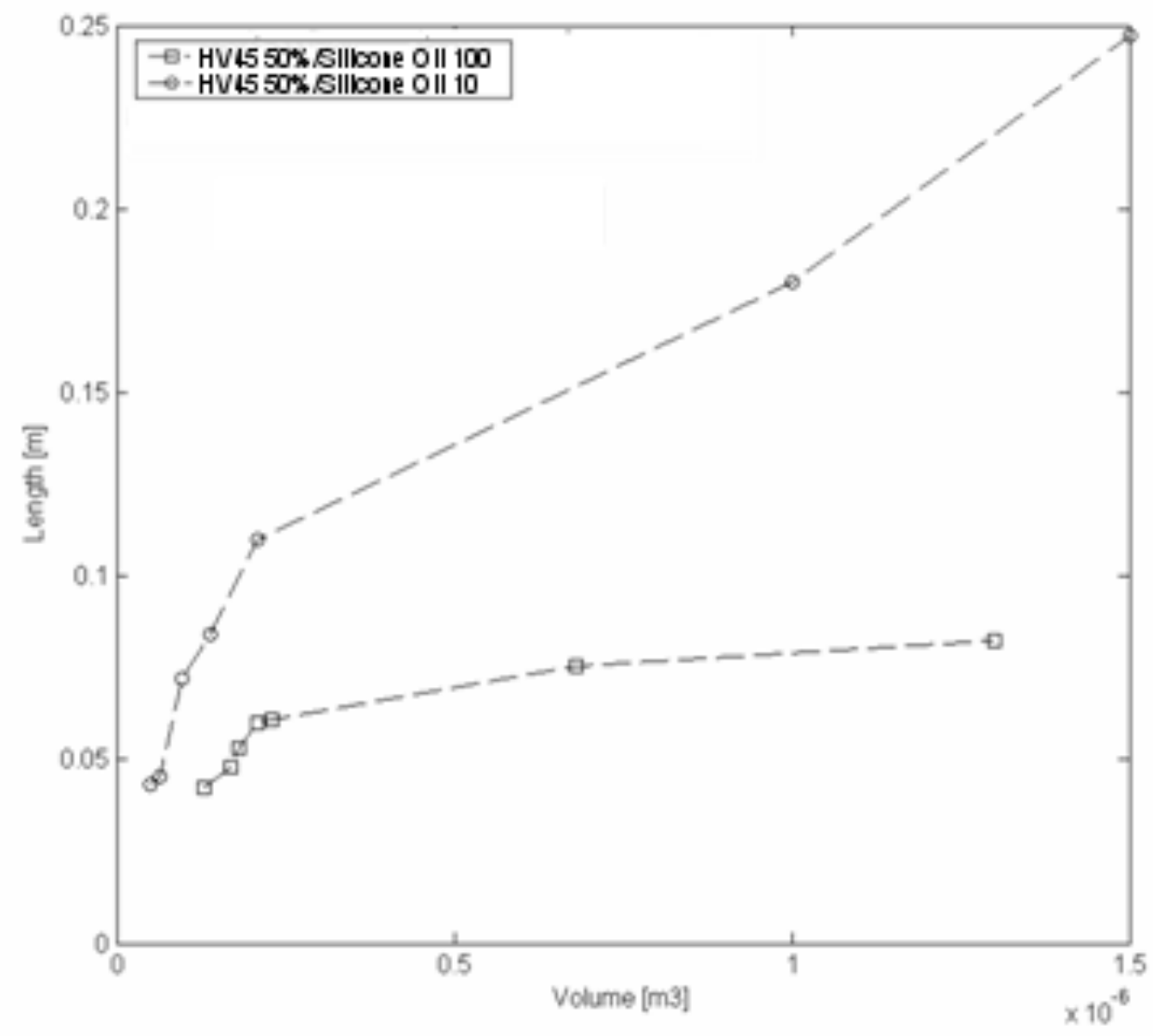




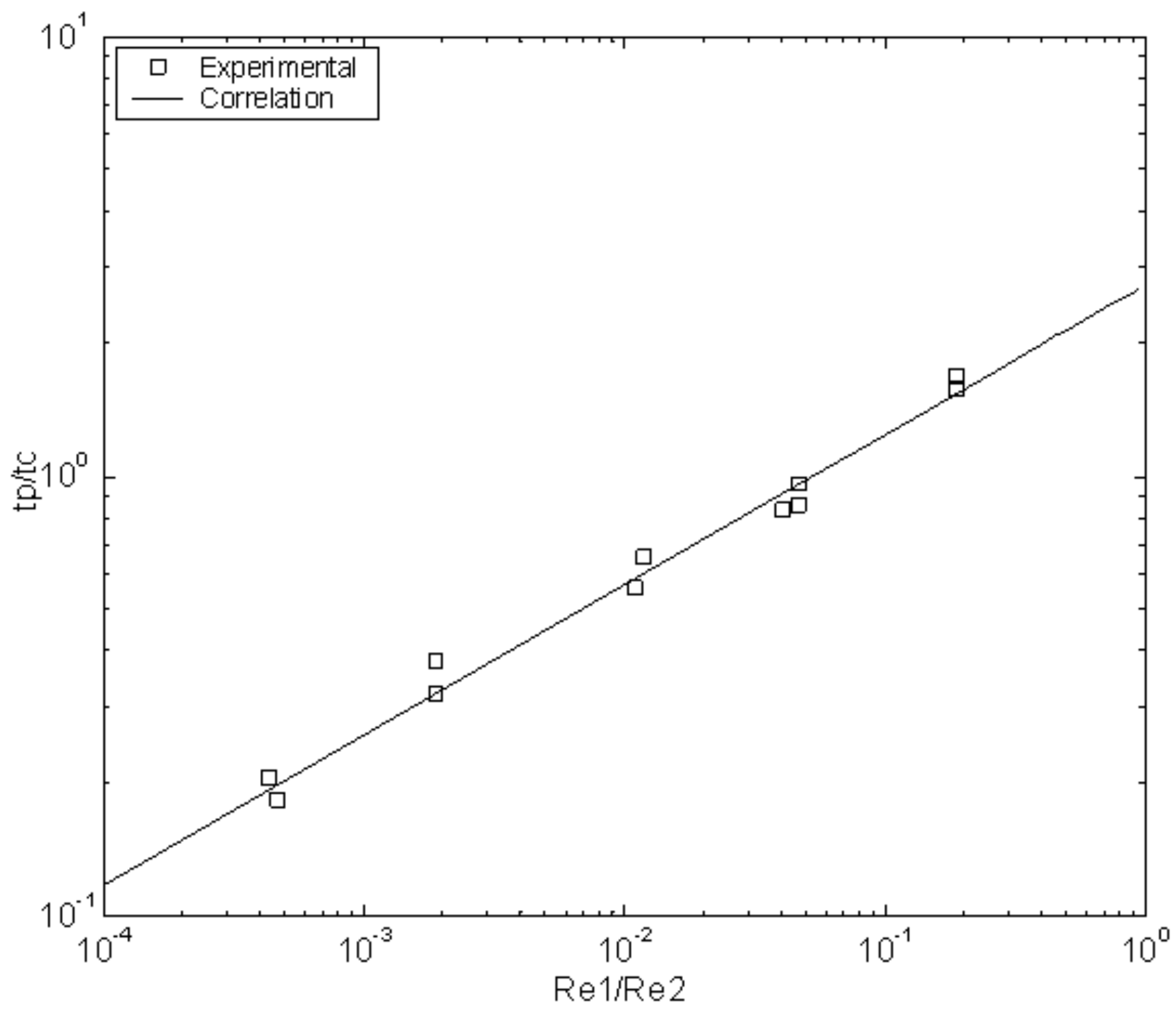




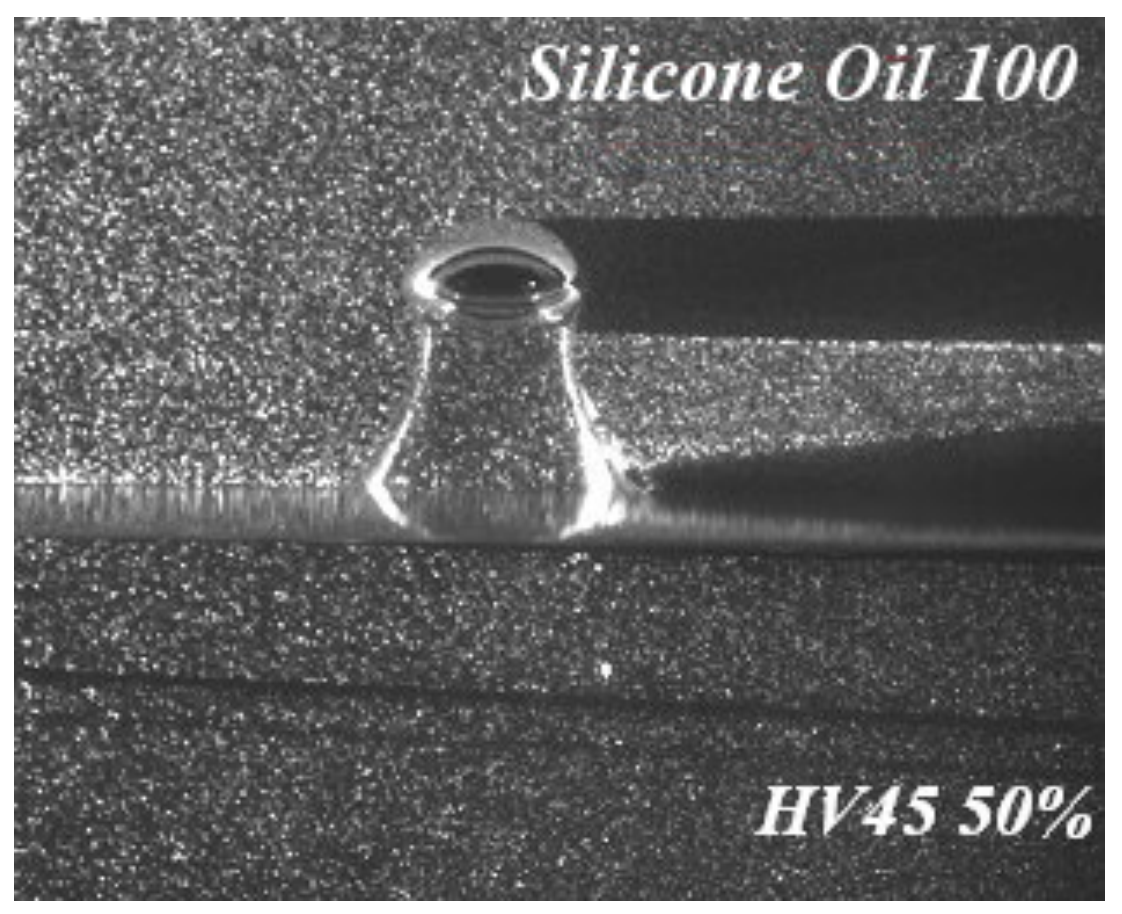



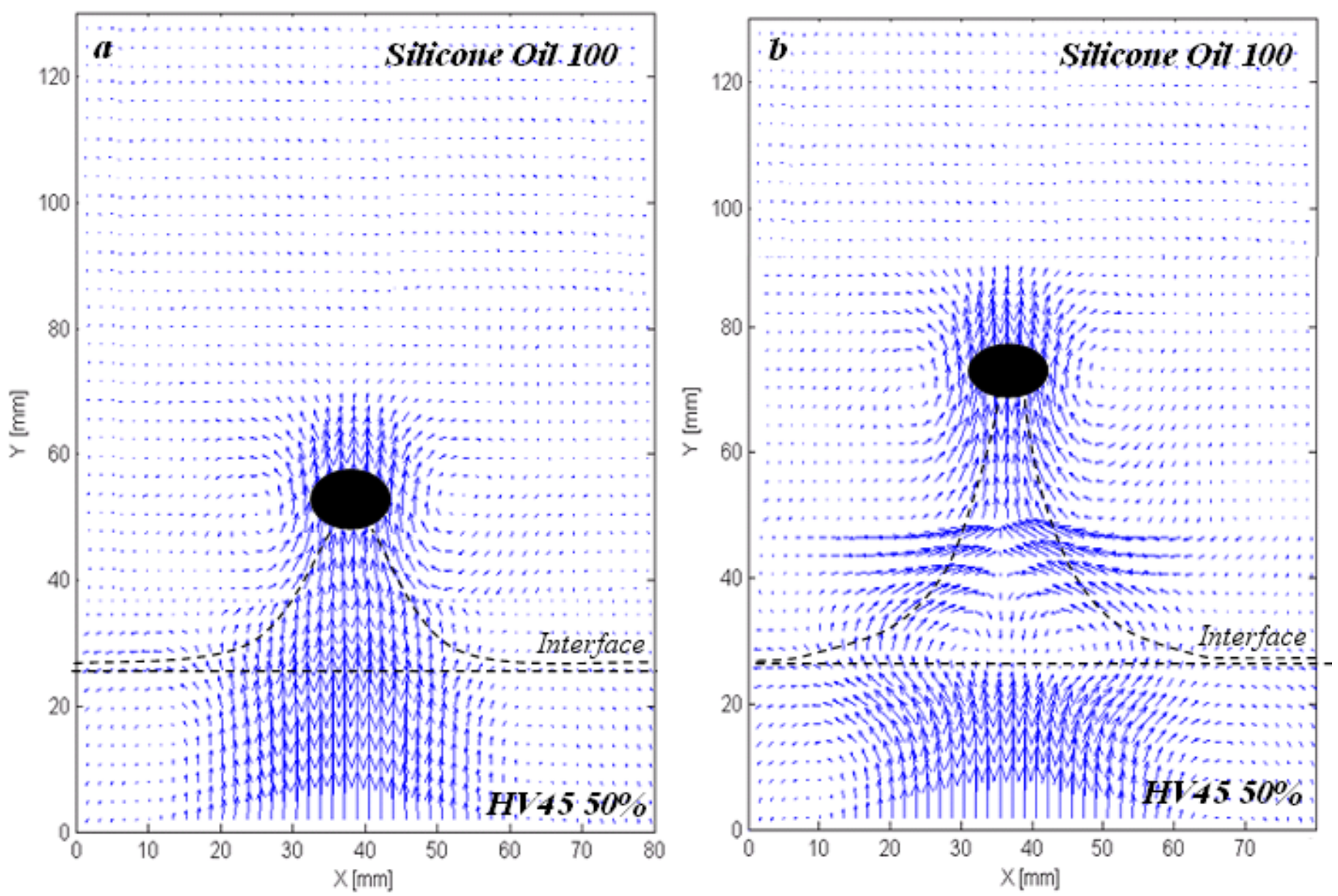

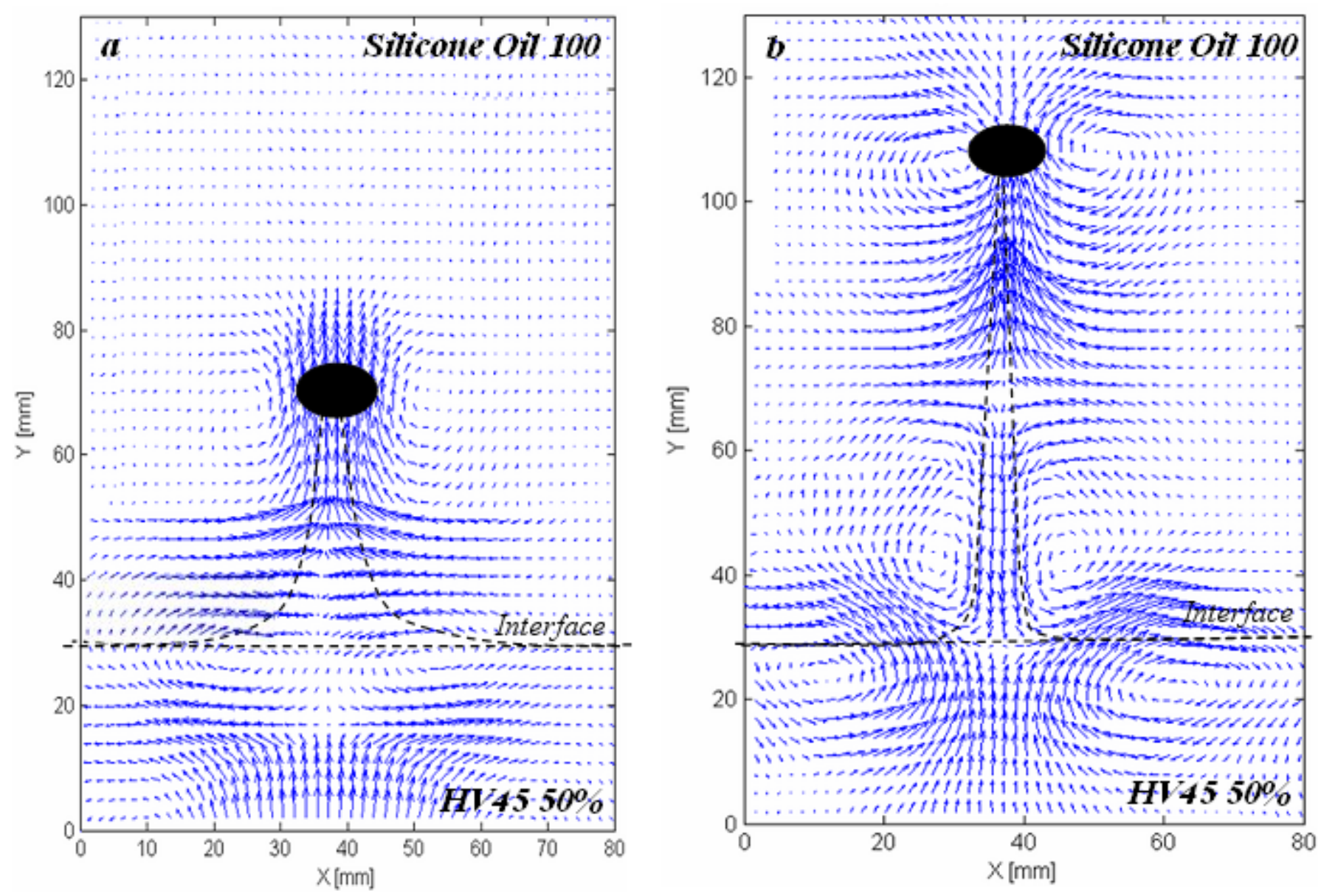

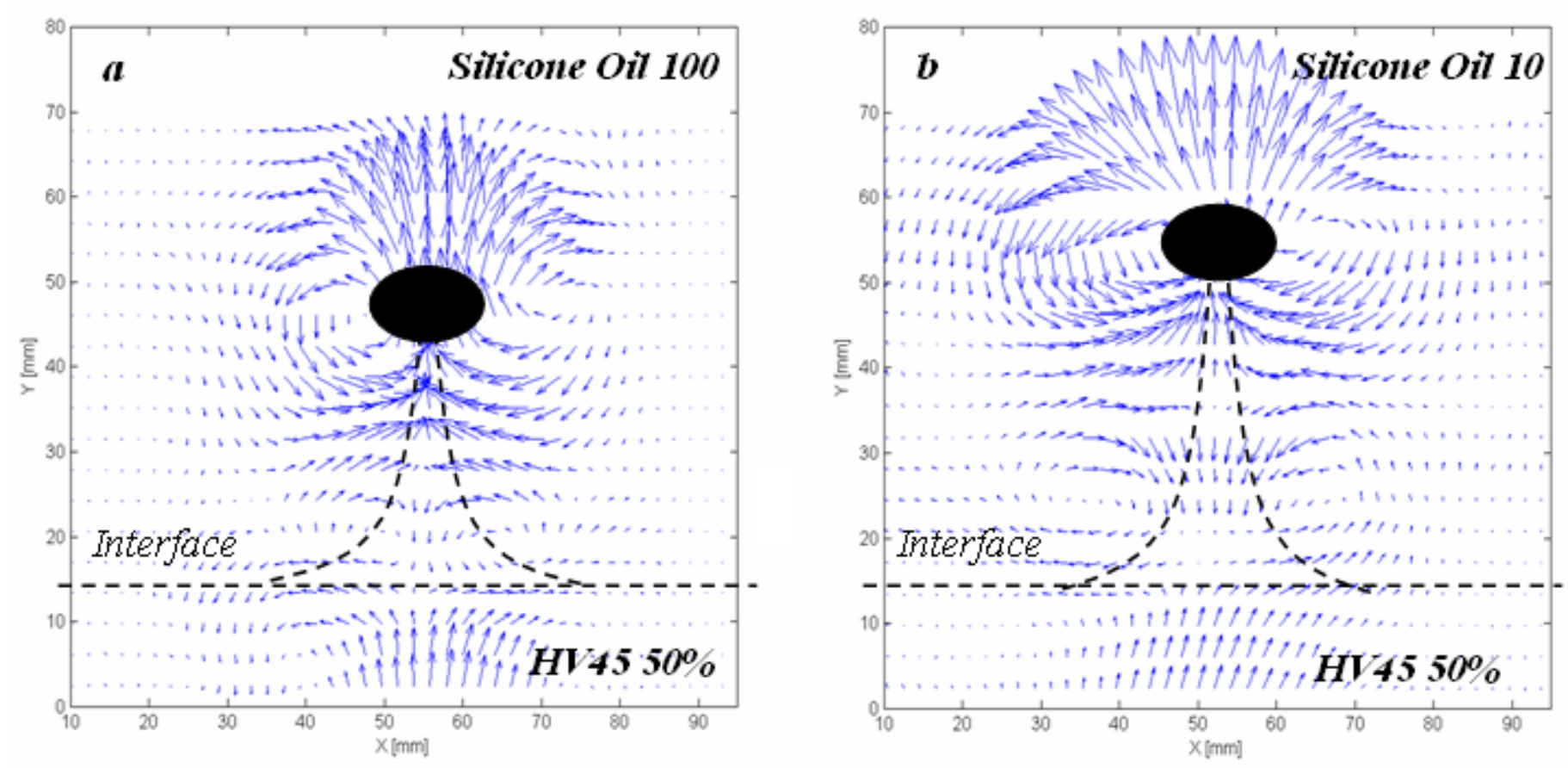